\title{
Polymer Science and Technology: An Australian Perspective
}

Text by David J. T HILL

Over the past fifty years, polymer science and technology has grown enormously, such that it now plays a vital role in almost all aspects of the global economy. In this respect, the two giants in the Pacific Basin have been Japan and the USA. Clearly, a major contributor to the growth within Japan has been the Society of Polymer Science of Japan, SPSJ. It has provided the basis for the communication and exchange of scientific knowledge and ideas through its various conferences, Journals and other activities.

Increasingly over the last quarter century, the SPSJ has extended its leadership contribution more broadly across the world stage, particularly in the Pacific Basin and especially in the Western Pacific. The introduction of an English version of KOBUNSHI last year is just one example of innovation by the SPSJ so as to embrace a wider international audience for the Journal and its other activities. Of course there are many other examples of important initiatives of the SPSJ, but in my view the most significant for the Pacific Region has been the founding of the Pacific Polymer Federation, PPF.

The PPF constitution was signed in Tokyo on October 19, 1987 at a ceremony hosted by the SPSJ. The six signatories were representatives of the SPSJ, the Division of Polymer Chemistry, American Chemical Society and the Polymer Division, Royal Australian Chemical Institute, RACI-PD, the three founding Societies. Since 1987 the PPF has become truly representative of the Pacific Basin, with Polymer Societies from most Pacific Nations now members. The objectives of the PPF are to encourage and facilitate: (i) interaction between polymer organizations involving the Pacific and (ii) the exchange of scientific knowledge, participation in national polymer meetings and visits by polymer scientists of the Pacific.

Both the SPSJ and the RACI-PD have embraced the PPF objectives by encouraging and regularly sponsoring Pacific Basin scientists to attend and deliver lectures at national polymer symposia and other meetings. As an example, in 2007 Professor Mitsuo Sawamoto of Kyoto University presented the Solomon Lecture Series, a prestigious series of lectures sponsored by the RACI-PD and delivered in Australia and New Zealand.

While national symposia and special lectures are important media for the exchange of scientific knowledge, in my opinion even greater benefits can be derived through direct research collaborations. Since the founding of the PPF, several research collaborations have been developed between members of the SPSJ and the RACI-PD. It would be impossible to mention all of these here, but I will highlight a few between polymer groups in Japan and Brisbane, simply as examples. In Brisbane, active polymer groups have been located at the three major Universities -The University of Queensland, UQ, The Queensland University of Technology, QUT, and Griffith University, GU.

The research groups of Professor Mikiharu Kamachi (Osaka University) and Professor Bunichiro Yamada (Osaka City University) have collaborated with the UQ group on studies designed to measure reliably the rate parameters

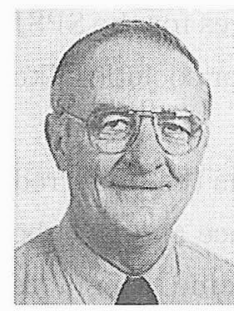

David J. T. Hill, Professor (d.hill@uq.edu.au)

Former President, Pacific Polymer Federation; Former Chair, Polymer Division, Royal Australian Chemical Institute. Department of Chemistry, School of Molecular and Microbial Sciences, The University of Queensland, Queensland 4072, Australia 


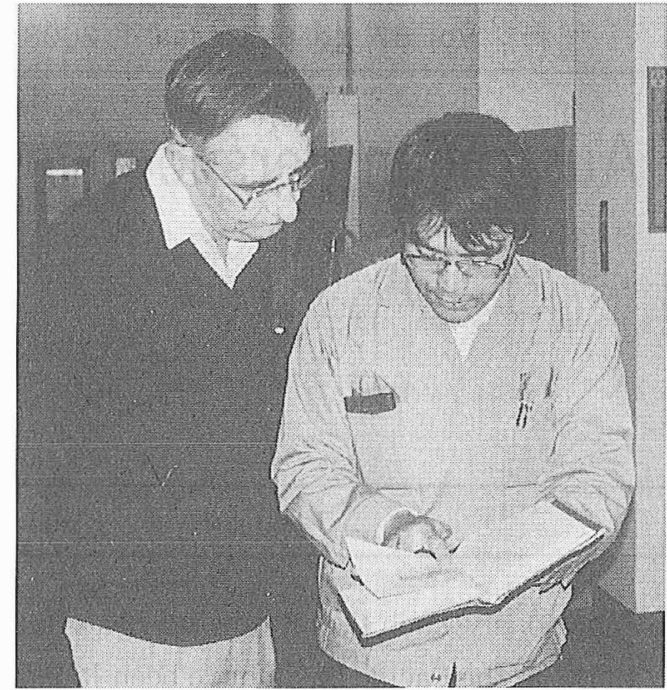

David and Kisaaki Kudoh at JAERI, 1994

$k_{\mathrm{p}}$ and $k_{\mathrm{t}}$ for polymerizations of some acrylates and methacrylates. These collaborations have involved both academic staff visits to exchange information and ideas and, more im portantly, of post-graduate students from Osaka during their $\mathrm{PhD}$ study. Professor Yamada's group and the GU group have also engaged in collaborative research. This involved the use of nitroxides to trap, identify and quantify the initial short-chain oligomers formed during free radical polymerizations. Professor Per Zetterlund, now at Kobe University, and Dr Tomoyuki Nakamura, NOF Corporation, Japan, were also involved in this collaboration.

The UQ group has also had collaborations with Professor Koichi Hatada (Osaka University) and Dr Tadao Seguchi (JAERI now JAEA) in the area of polymer radiation chemistry. In 1994 I spent a sabbatical leave as a JAERI Fellow working with Dr Seguchi and his colleagues at the labs in

Takasaki. We studied the radiation chemistry of several aromatic polyimides. While at JAERI, I also worked closely with Professor Hisaaki Kudoh, who is now at the University of Tokyo. In addition to my sabbatical and short staff exchange visits, this collaboration involved two PhD students from UQ obtaining scholarships to carry out research at JAERI as part of their degree. The collaboration is still active through Professor Kudoh and Professor Andrew Whittaker, now the leader of the UQ chemistry group, who have been investigating the irradiation of composites of carbon nanotubes and polyimides for aerospace applications.

Professor Minoru Terano of JAIST in Ishikawa and Professor Graeme George of the Polymer Materials Science Group at QUT collaborate on studies of polyolefin stability, involving both staff and student exchange. Recently they have chaired a conference on the Ultimate Stability of Nano-Structured Polymers and Composites at JAIST.

In 2007 Shuko Suzuki from the QUT group broke new ground by submitting the first polymer PhD thesis by a Japanese student at a Brisbane University. She is now working with Professor Yoshito Ikada at Nara Medical University.

There have also been exchanges of PhD graduates. Dr Qipeng Guo, a PhD student with Professor Kiyoshi Takahashi at Kyushu University, has worked at UQ with Professor Peter Halley, Dr Phuong Ghi (UQ) worked with Professor Tetsuo Asakura at Tokyo University of Agriculture and Technology and Dr Ben Goss (QUT) with Professor Minoru Terano at JAIST.

The students studying polymer science today represent the future of the SPSJ, the RACI-PD and, more broadly, tomorrow's polymer science and technology. In our global world of the $21^{\text {st }}$ century, it is just as important for these students to have aspirations for international experience as it is for them to have national goals. In addition, internationally it is important for all of us to be aware of cultural differences and sensitivities. In my opinion, the best way to achieve these aims and obtain experience is through post-graduate student and post-doctoral exchange programs. Thus, I encourage you to consider the many benefits that our students, the SPSJ and we can derive from being involved in collaborative programs and research. The RACI-PD web site (http://www.polymer.org.au/) lists the major polymer research groups in Australia and their interests.

The nature of polymer science and technology is ever changing and increasingly the applications of polymers are expanding. So we see polymers now performing significant roles in other disciplines, such as pharmacy, medicine, biology, agriculture, engineering, aerospace, etc. This expansion will provide new challenges for the SPSJ as the research interests of its members diversify. It will become increasingly important for polymer societies like the SPSJ to develop relationships with societies representing other scientific disciplines.

Over the last $5-10$ years we have witnessed increasingly the use of the internet by our students as the preferred means for communicating and obtaining information. Today web-based facilities such as My-Space and U-Tube are our young people's every-day messaging media. Clearly, in the future, use of the www will become even more 
mundane, and this will surely provide the SPSJ and polymer scientists with many new opportunities and challenges. For example, questions will arise such as: will our Society Journals survive in their current form; for how much longer will we receive Polymer Preprints on a CD; will more conference presentations be "beamed-in" on the day; will we be able to attend conferences in our office via interactive TV; will we have to consider a new category of cyber-space conference delegate; should we be running polymer training courses for scientists of cognate disciplines? Some of these questions are already being given serious consideration.

Polymer science and technology and the roles of societies like the SPSJ and the PPF will remain bright into the foreseeable future, but no doubt there will be many changes in our discipline and in the ways we do things. We have made a start on promoting research collaborations between groups in our two countries, but opportunities exist for many more groups to be involved in exchange programs. In this context, I invite you to make contact with an Australian group with a view to initiating a program of collaborative research, taking a period of sabbatical study or applying for a post-doctoral position. 